\title{
CONSTRUINDO SABERES E CONHECIMENTOS GEOGRÁFICOS COM PROFESSORES EM SERVIÇO NAS ESCOLAS DO CAMPO ${ }^{1}$
}

\author{
BUILDING KNOWLEDGE AND GEOGRAPHIC SKILLS WITH TEACHERS \\ WORKING IN COUNTRYSIDE SCHOOLS
}

\author{
CONSTRUYENDO SABERES Y CONOCIMIENTOS GEOGRÁFICOS COM \\ MAESTROS EM ATENCIÓN EN LAS ESCUELAS DEL CAMPO
}

\author{
Alexandra Maria de Oliveira - Universidade Federal do Ceará - Fortaleza - Ceará - Brasil \\ alexandra.oliveira@ufc.br
}

\section{Resumo}

No movimento de luta pela reforma agrária, a escola do campo se revela como um projeto voltado para atender as necessidades dos pobres do campo e deve ser compreendida como um processo que contempla, em sua lógica, uma política que pensa a educação como parte constitutiva do desenvolvimento dessas regiões. Este trabalho pretende apresentar uma leitura sobre os desafios colocados na formação dos professores de Geografia em escolas do campo. A pesquisa foi desenvolvida em trabalho conjunto com professores de ensino fundamental no Assentamento 25 de Maio no município de Madalena, Ceará. Ao longo do processo, ficou constatado que as mudanças educacionais presentes no campo brasileiro exigem a leitura e confrontação de dois projetos inconciliáveis: 0 oficial e o popular.

Palavras-chave: ensino de geografia, professores assentados, escola do campo.

\section{Abstract}

In the movement of struggle for agrarian reformation, the countryside school comes out to be considered a project which should meet the needs of the rural poor and must be understood as a process that includes, in its logic, a policy that thinks education as a constitutive part of development of this field. This paper aims to present a lecture on the challenges faced by the training of Geography teachers in countryside schools. The survey was developed with primary school teachers in a settlement called 25 de May in the municipality of Madalena, Ceará. Throughout the process it was found out that educational changes present in the Brazilian countryside today are supposed to be considered by two irreconcilable projects: the official and the popular ones.

Key words: geography education, settled teachers, countryside school.

\section{Resumen}

En el movimiento de lucha por la reforma agrária, la escuela del campo se revela como un proyecto direcionado a atender las necesidades de los pobres del campo y debe ser comprendida como un proceso que contempla en sú parte constituyente del desarrollo del campo. Esta investigación pretende presentar una lectura sobre los desafios puestos en la formación de maestros de Geografia en escuelas del campo. La investigación fue desarrollada en un trabajo conjunto con maestros de enseñanza fundamental en el Asentamiento 25 de Mayo, en el municipio de Madalena, Ceará. Al largo del proceso constatose que los cambios educacionates presentes en el campo brasileño en la actualidad, por la interpretación de dos proyectos inconciliables: el oficial y el popular. Palabras clave: enseñanza de geografia, maestros asentados, escuela del campo. 


\section{Introdução}

Buscando fortalecer a relação universidade e escola básica, a pesquisa "Transformações territoriais no campo: práticas, saberes e poderes na relação sociedade-natureza" tem procurado discutir a contribuição da Geografia, como disciplina escolar, na leitura da realidade social do campo. Nesse texto específico, abordo um momento do processo de socialização de professores e alunos do departamento de Geografia da UFC com professores e alunos da Escola de Ensino Fundamental Jette Joop, localizada no Assentamento 25 de Maio em Madalena, Ceará.

A Geografia, como disciplina escolar, exerce papel relevante no entendimento dos processos que envolvem a relação entre a sociedade e a natureza. O estágio curricular tem possibilitado o reconhecimento de nossa prática docente no trabalho com a disciplina no mundo da escola. A escola do campo é vista como uma proposta que nasceu de demandas dos movimentos camponeses em busca da construção de uma política educacional para os acampamentos e assentamentos de reforma agrária. Essa interpretação é relevante para a compreensão da realidade que envolve a escola do campo, que se encontra no processo de espacialização da luta camponesa.

Os processos de espacialização e territorialização dos movimentos sociais no campo e a contribuição da Geografia agrária na leitura sobre as transformações territoriais recentes presentes no campo brasileiro têm sido o fundamento de uma matriz teórica que tem por base a teoria social. Essa matriz fundamenta-se em trabalhos pioneiros na análise sobre os movimentos socioterritoriais e a educação do campo com ênfase em metodologias de aprendizagens em conjunto - com respeito, autonomia e dignidade -, valores que são necessários à educação do povo do campo.

\section{Geografia e escola nas lutas no campo}

A Geografia brasileira tem em sua sistematização um vasto campo teórico pautado na discussão sobre a história, a origem e os processos que compõem a formação territorial brasileira. O paradigma da questão agrária trouxe influências teóricas e práticas ao estudo do movimento desigual, contraditório e combinado do território brasileiro e suas transformações recentes. Nessa construção, o território tem sido um conceito chave que se apresenta no centro da discussão. 
Na Geografia agrária, o estudo do território como categoria primordial de investigação tem sido fundamentado em livros, teses e dissertações por autores como Raffestin (1993), Oliveira (1998) e Fernandes, (2006). Para Oliveira (1998), o território deve ser entendido como síntese contraditória da espacialidade que a sociedade tem e desenvolve. Os territórios são espaços geográficos e políticos, onde os sujeitos sociais discutem, planejam e constroem seus projetos de vida e de lutas sociais. No processo, os sujeitos sociais organizam-se por meios de relações de classe para desenvolver seus territórios. Nesse contexto, Fernandes (2006) acrescentou o fato de que a educação, a cultura, a economia e outras dimensões mais propostas pelos movimentos camponeses não existem fora do território. Assim, esse autor mostrou que na Geografia agrária é importante compreender a dimensão educativa contida nos processos de espacialização e territorialização da luta pela terra no Brasil.

De acordo com Oliveira (1998), a formação territorial capitalista no campo brasileiro está marcada pelos processos de territorialização do capital e de monopolização do território pelo capital, fenômeno ainda encontrado e, contraditoriamente, marcado pela expansão da agricultura camponesa. Essa agricultura tem nas ocupações, nos acampamentos e nos assentamentos rurais ações efetivas de resistência e luta pela reforma agrária.

A leitura geográfica proposta tem como pressuposto a educação do campo, que se encontra na denominada Pedagogia do Movimento (Caldart, 2004). A discussão original dos conceitos de educação do campo, pedagogia do movimento e escola do campo nasceu de demandas dos movimentos camponeses para a construção de uma política educacional voltada para os acampamentos e assentamentos de reforma agrária brasileiros. Assim, a posse da terra passa a ser condição para a viabilização de um conjunto de outras lutas, como a luta por estrutura viária básica, por escola e por educação contextualizada. Esse é um fato extremamente relevante na compreensão dos processos políticos e sociais que envolvem a escola do campo. De acordo com Fernandes (2006), foi da demanda específica por educação nos acampamentos e assentamentos do movimento dos trabalhadores rurais sem terra que nasceram o Programa Nacional de Educação na Reforma Agrária (Pronera) e a Coordenação Geral de Educação do Campo. Nesse sentido, a educação do campo deve ser compreendida como um processo em construção que contempla, em sua lógica, a 
política que pensa a educação como parte constitutiva e essencial para o desenvolvimento do campo a partir do projeto popular.

O movimento de luta pela reforma agrária nos últimos anos desenvolveu e conquistou diferentes dimensões sociais, políticas, econômicas e territoriais no País. No Ceará, a conquista de frações do território capitalista que estão sendo apropriadas pelos camponeses na luta pela terra tem contribuído para o fortalecimento do setor de educação nos assentamentos. Após uma década, o Pronera foi permitindo a conquista de espaços e modalidades de ensino, que se ampliam fortalecendo a relação entre campo e cidade ou entre universidade e escola básica do campo. As lutas do povo acampado e assentado dentro e fora dos acampamentos e assentamentos tornaram-se um recurso poderoso no que se refere à espacialização das lutas camponesas. Estas estão desenvolvendo, nos territórios conquistados, o sentido de trunfo proposto por Raffestin (1993), quando este autor defende esse sentido como um poderoso conceito do campo geográfico.

A análise da educação presente no campo brasileiro pressupõe, nos dias atuais, a leitura de dois projetos inconciliáveis: o projeto oficial e o projeto popular. Um projeto majoritário, feito em nome das relações hegemônicas, que acaba sendo pactuado, e um outro popular, defendido pelos movimentos sociais e representações camponesas, que atende às necessidades básicas do povo do campo. Assim, a manutenção de diferentes formas de produção e trabalho na terra camponesa, a luta por direitos e, ainda, por uma educação do campo, é parte constitutiva da luta pela reforma agrária dinamizada no seio dos movimentos e das representações camponesas.

A construção recente de uma leitura sobre o campesinato brasileiro e a luta por uma educação que contemple os saberes, as práticas e as experiências no campo têm sido apresentadas por Stedile e Fernandes (1999) e Arroyo e Fernandes (1999), entre outros.

No Ceará, a luta pela terra, construída historicamente por sujeitos sociais, muitas vezes geograficamente isolados nos sertões, tem, nos dias atuais, como resposta a suas ações, a conquista de frações do território capitalista, que vai para a mão dos camponeses organizados em movimentos e representações camponesas. Assim, não há, portanto, como desconsiderar a importância dos assentamentos rurais no País (Leite et. al., 2004). Para esses autores, os assentamentos são vistos como ponto de chegada 
de um processo de luta pela terra e tornam-se ponto de partida para uma nova condição de vida. Eles estão construindo um novo perfil produtivo nos municípios, na organização social da produção e da família, nas condições de vida e na participação política local e regional.

Como afirma Arroyo (2004), a organização social e a luta por direitos, trabalho e educação são ações constitutivas de um processo em que o campesinato se afirma como sujeito cultural. Por isso, a produção não deve ser separada da educação e da escola. A produção do trabalho familiar na leitura pedagógica dos movimentos sociais e das representações camponesas é mais do que produção, é momento de encontro e de trocas de saberes no processo de aprendizagem. Desse modo, estudar saberes e práticas pedagógicas do campo coloca o estudioso diante do desafio de dar sentido às palavras valendo-se do conhecimento específico e das experiências individuais e coletivas construídas na convivência com o povo do campo.

O processo de investigação tem sido desenvolvido com professores licenciados no curso de Pedagogia e Pedagogia da Terra que trabalham com as séries iniciais do ensino fundamental e são considerados polivalentes. Conforme Oliveira (2009), os currículos escolares e o material didático encontrados na escola, de uma maneira geral, desconsideram a diversidade de fatos e ações da realidade local, realizando, assim, um ensino estagnado, descontextualizado, porém comprometido com a aceitação passiva de novas formas de socialização do capitalismo ou com relações propostas pela política educacional oficial. Paralelamente a isso, a escola do campo é produto de seus sujeitos, os trabalhadores e trabalhadoras do campo, que carregam suas especificidades construídas nas trajetórias de lutas de suas organizações. A escola do campo está vinculada aos interesses dos camponeses, uma educação contextualizada e a favor de um projeto de desenvolvimento popular para o campo.

\section{Oficina geográfica com professores em serviço nas escolas do campo}

A proposta de trabalhar com uma oficina geográfica usando professores de Geografia das escolas do campo foi um desafio que surgiu durante as aulas de prática de ensino nessa disciplina e em visitas de acompanhamento da pesquisa nos assentamentos rurais. No planejamento do estágio, a ideia do uso da escola como laboratório de estudos foi substituída pela 
ideia da escola como o lugar de trocas e construção de conhecimentos e aprendizagens significativas. No processo, o contato inicial com a comunidade do Quieto foi feito através de viagens de reconhecimentos das escolas no mundo rural. Após visitas de campo e participação em reuniões pedagógicas na secretaria de educação do município de Madalena, surgiu a proposta de construir uma oficina geográfica com os professores da escola básica, com o intuito de fortalecer o ensino da Geografia discutido na escola. A proposta foi aceita pelo grupo e encaminhada pelos colegas que viabilizaram o trabalho com o compromisso de que fosse estabelecida uma atividade em conjunto, a ser realizada na escola do Quieto, Assentamento 25 de Maio.

O Assentamento 25 de Maio está composto de dezoito comunidades distribuídas numa área localizada entre os municípios de Madalena, Boa Viagem e Quixaramobim, na depressão sertaneja do sertão central cearense, distante cerca de $150 \mathrm{~km}$ da cidade de Fortaleza e $30 \mathrm{~km}$ do núcleo urbano do município de Madalena. A opção pelo estudo de caso e a escolha da comunidade do Quieto se deu quando a equipe foi informada a respeito da proposta pedagógica desenvolvida pela escola, que apresentava traços da pedagogia da terra. Um outro fator que determinou a escolha foi a disponibilidade da comunidade-escola em trabalhar com a proposta oriunda da universidade.

O Assentamento 25 de Maio foi fruto de uma ocupação organizada pelos camponeses e apoiada pelos sindicatos rurais, pela Comissão Pastoral da Terra (CPT) e pelo MST. De acordo com os camponeses, havia a necessidade de uma organização política capaz de superar a situação de submissão em que se encontravam. O dia 25 de Maio, data marcada para a ocupação organizada pelo MST, deu nome à antiga fazenda São Joaquim, de propriedade do sr. Wicar Parente Pessoa. Abrangendo uma área de 22.992,00 ha, o imóvel foi considerado improdutivo para o cumprimento da função social, compreendendo terras exploradas e mata virgem. Na propriedade residiam cinquenta famílias na condição de moradores, que foram inseridos no assentamento e na luta pela reforma agrária. Completados 15 dias da ocupação, foi assinada a emissão de posse da terra em 9 de junho de 1989. Para Azevedo (1992), foi esse o processo mais rápido ocorrido no estado até então, só tendo sido possível em razão da organização do MST e da conjuntura política existente em níveis estadual e federal, graças às possibilidades advindas da implantação do primeiro Plano Nacional de Reforma Agrária. 
O atual prédio da escola no assentamento foi construído graças à doação de recursos financeiros feita por uma cidadã alemã (Jette Joop), mediante a intermediação da Cruz Vermelha Brasileira, em parceria com a prefeitura de Madalena. Essa atitude contribuiu para que a comunidade a homenageasse, colocando seu nome na placa comemorativa fixada no novo prédio. A escola do Quieto (como é conhecida na localidade), além de ser referência em termos de organização e trabalho no assentamento, apresenta-se em excelente estado de conservação, condição necessária para a prática pedagógica proposta. O prédio da escola, construído ao lado de um posto de saúde há cerca de dois anos, possui seis salas de aula, uma secretaria, uma cozinha e três banheiros. Antes do prédio atual, a escola funcionava em um antigo galpão da cooperativa que ainda hoje mantém salas de aula e área de estocagem de parte dos produtos oriundos do assentamento.

Nas visitas de campo, a equipe da universidade sempre foi bem aceita por professoras que acatavam a proposta e contribuíam com a abertura do diálogo, mediante a aplicação de entrevistas e a troca de material didático. Após oito meses de observação, levantamento e sistematização dos dados, a oficina foi proposta para o período do planejamento pedagógico municipal - janeiro de 2009. Na construção do diálogo, muitas das professoras mostraram a necessidade de adotar um instrumental que as ajudasse em sua prática cotidiana. Nesse sentido, as atividades emergiram das necessidades reais do professorado local. As atividades foram compostas de aulas expositivas e dialogadas, abordando temáticas como a questão da propriedade privada no Nordeste, a luta pela terra, as paisagens geoambientais e a educação ambiental na prática pedagógica dos professores de Geografia. Também foi proposto um trabalho de campo na região do entorno do assentamento, com o objetivo de discutir na prática as questões teóricas propostas.

A abertura dos trabalhos foi iniciada com uma mística que enfatizou a educação do campo e a união entre os moradores da cidade e do campo na luta por uma reforma agrária que contemplasse os temas escola, terra e dignidade.

Para Stedile e Fernandes (1999), a mística é a força, a energia cotidiana, que tem animado a família Sem Terra a continuar na luta, ajudando cada pessoa a enxergar e a manter a utopia coletiva. É o momento em que se fortalece aquele sentimento materializado em símbolos, fazendo o gru- 
po sentir que não está sozinho, e que são os laços que unem uns aos outros lutadores que dão mais força para prosseguir na construção de um projeto coletivo. No MST, a mística tem uma dimensão educativa muito importante. Ajuda os militantes mais antigos a cultivar os valores e a memória simbólica que os mantêm a caminho. Para as novas gerações ou para cada sem-terra que entra no movimento, ajuda na disposição pessoal de entrar no processo e a vivenciar as ações de forma mais humana e plena. De fato, é uma espécie de ritual de acolhida, que faz as pessoas se sentirem parte do movimento mesmo antes de conhecer toda a sua dinâmica.

Todas as dimensões da formação humana, da sociabilidade, da integração e do compromisso entre os grupos estiveram postas nesse momento de acolhida, considerado por todos como um momento repleto de alegrias e intencionalidades. A esse respeito, não há como não concordar com Maia (2008), quando esse autor analisa a mística no MST como um processo educativo. Ao final desse momento e como uma forma de mostrar o orgulho, a organização e a força do Movimento, os militantes entoaram o hino do MST antes de passar a palavra para a equipe de professores da UFC.

Após uma breve apresentação do grupo, a equipe contextualizou e apresentou os objetivos da oficina geográfica, demonstrando compromisso e respeito com o movimento de educação do campo proposto pelo MST. A luta pela reforma agrária foi abordada com base em uma leitura dialética marxista sobre o papel da propriedade privada da terra no Nordeste. Duranate o debate, foi possível ampliar a discussão sobre a concentração fundiária, a função social da terra, o significado dos movimentos sociais e das representações camponesas na luta pela terra, e a conquista de frações do território.

A leitura sobre unidades geoambientais e as diferentes paisagens existentes no semiárido brasileiro foi mais um tema abordado. As aulas expositivas dialogadas procuraram desvelar as especificidades dos diferentes ambientes que compõem o território brasileiro e, em especial, exploraram a realidade cearense.

O trabalho de campo foi proposto como um instrumento fundamental para a formação dos docentes que trabalham com o ensino de Geografia. A área priorizada para o estudo foi o sertão central. Foi iniciada no interior do assentamento discutindo-se a questão da propriedade privada e a constituição das relações sociais no campo com base em evidências 
que iam sendo observadas, tais como: a diferença no sentido da construção de cercas de proteção e cercas de divisão presentes ao longo das propriedades, a forma como a pecuária extensiva é utilizada como reserva de valor e/ou reserva patrimonial pelos proprietários de terra rentistas, ou seja, aqueles que se apropriam da renda da terra sem nada nelas produzir e as diferentes funções que a terra vai adquirindo a partir do uso social.

Durante o trajeto Madalena -> Quixeramobim -> Quixadá -> Choro -> Madalena foram sendo relizadas paradas para fazer a leitura geográfica da diversidade paisagística presente nas subáreas contidas na paisagem dominada pela depressão sertaneja que se apresenta interrompida por maciços residuais (serrotes) e relevos residuais (inselbergs). Essas formas de relevos (plano e suave ondulado), em contato com o clima semiárido (regime hídrico concentrado), constituem os tipos de vegetação denominados caatinga arbustiva e arbórea, típicas da região.

Foi possível perceber ainda a vulnerabilidade natural dos solos encontrados: neossolos litólicos (rasos e pedregosos), luvissolos (rasos e argilosos) e vertissolos (pouco profundos e muito argilosos) no tocante a manejo e usos com base em práticas inapropriadas como as queimadas, os plantios em áreas de forte declive ou, ainda, o uso excessivo. Como consequência, foi possível detectar várias manchas de vegetação com formações secundárias e solos com alterações na composição original, o que revelou um quadro com fortes traços de degradação ambiental.

Assim, foi possível constatar que a região possui solos produtivos do ponto de vista de sua fertilidade natural, porém a falta de água e de orientação técnica têm contribuído para o uso insustentável deles, havendo, portanto, uma predisposição ao processo de desertificação na região. As terras no assentamento poderiam ser mais produtivas se, de fato, a orientação técnica estivesse presente, já que a existência dos açudes tem amenizado o problema da falta de água. Outros temas como educação ambiental, qualidade de vida, moradia e saúde foram intensamente trabalhados com os professores. No processo, uma nova compreensão geográfica da diversidade ambiental presente no sertão central cearense foi sendo formada. Em todo o trabalho de campo foram feitas abordagens e anotações, e foram sendo feitos questionamentos sobre as condições socioambientais presentes na área percorrida. No contato com a realidade, os professores foram tomando ciência do grau de degradação ambiental presente no sertão e da necessidade de fortalecer uma campanha de com- 
bate à falta de uso de técnicas contra a degradação da natureza, ou a favor da educação ambiental.

Ao final da oficina, houve um momento de socialização do trabalho de campo, no qual foi fortalecida a importância da relação entre o conhecimento específico curricular e os saberes práticos com base na experiência. Também foram levantados problemas práticos como o pouco conhecimento dos professores a respeito da Geografia como ciência que discute o espaço; a necessidade de propor nas aulas conteúdos relacionados com as formas de trabalho e uso da terra; e as relações entre as lutas sociais e a educação ambiental. Foram propostas discussões que possam trazer procedimentos e atitudes diferenciados na relação dos camponeses com o trabalho agrícola, e houve um diálogo a propósito da elaboração de um relatório de campo.

Foram, ainda, distribuídos ou indicados textos como contribuição para o embasamento teórico e para a reflexão da prática docente. Essa atividade procurou atender aos seguintes princípios: trabalhar a Geografia escolar, os conhecimentos e as experiências de todos (professores, comunidade e alunos) como base para o ensino; levar ao conhecimento do professorado diferentes linguagens para a construção da Geografia escolar; elaborar práticas metodológicas de ensino que permitam explorar leituras do campo a partir das unidades geoambientais (depressão sertaneja, planícies fluviais, maciços residuais e relevos residuais) presentes na região. Foi, portanto, um trabalho dialogado e construído em conjunto com os professores com base nas necessidades presentes em suas práticas docentes.

Desenvolver a pesquisa acadêmica com a Geografia e a formação de professores tem sido uma proposta bastante discutida e desenvolvida no trabalho docente (Pontuschka e Oliveira, 2002). A prática com os professores da escola do campo foi uma opção tomada em conjunto e considerada uma surpresa gratificante por parte dos sujeitos sociais envolvidos. Essa leitura revela, por um lado, que a relação entre a universidade e a escola básica do campo está posta como um desafio em nossa formação. E, por outro lado, demonstra que, mesmo com todos os seus limites, a Geografia tem muito a contribuir com a escola do campo, como mostraram as falas a seguir:

O trabalho de vocês foi bom porque a gente vai conhecendo o que nunca conheceu e reconhecendo o que já conhecia. Isso vai ajudando uns e outros a se unir e se entender. (Sr. Vicente - liderança) 
A troca de experiência vivenciada na interação entre os participantes nos possibilitou uma troca de experiência, ou seja, mais aprendizagem sobre o nosso lugar. (Profa. Eliane)

Foi muito bom trabalharmos juntos. Fortaleceu bastante possibilitando-nos mais subsídios para intervir de forma consciente junto aos nossos educandos. Espero que outros momentos aconteçam. (Profa. Ecília)

Os relatos apresentados pelos professores foram fundamentais para a continuidade da relação proposta inicialmente. Esta etapa foi encerrada com satisfação, no tocante aos objetivos propostos para o período específico, muito embora esteja presente a consciência de que é preciso um trabalho contínuo comprometido com o processo de lutas camponesas. Também ficou evidente a necessidade do retorno ao assentamento com o fito de produzir instrumentos teóricos e práticos cada vez mais eficazes no trabalho de leitura da relação entre a escola do campo e a geografia escolar.

\section{Considerações finais}

O trabalho de pesquisa e extensão na relação entre a escola básica do campo e a universidade vai-se ampliando e aperfeiçoando, em parte, por intermédio da prática. Há uma grande diferença no modo como desenvolvemos a oficina com os professores em serviço na escola do campo e os famosos "pacotes educativos" desenvolvidos no interior de gabinetes burocráticos que, muitas vezes, são impostos aos professores. A ação de professores e pesquisadores tem-se transformado a partir da sua prática pedagógica, refletida e analisada em conjunto com outros professores, sujeitos sociais na luta pela terra e pela justiça social. O trabalho de ação-reflexão-ação na prática docente tem permitido o desenvolvimento de educadores que assumem para si o compromisso com a transformação da realidade em que atuam.

A forma dialogada de pensar o conhecimento como um saber em conjunto contribuiu para uma avaliação satisfatória por parte da comunidade e dos corpos docente e discente envolvidos nos trabalhos. Na avaliação final ficou claro que, no início das atividades, o professorado teve dificuldades para entender o que exatamente seria desenvolvido na oficina. A própria linguagem foi algo que precisou de ser trabalhada para 
poder ser entendida. A equipe optou por ir (re)construindo as atividades em campo e respeitando a dinâmica da escola e da comunidade, assim como os limites entre os professores. Assim, todas as atividades foram refeitas no grupo e apresentadas e novamente modificadas, se preciso fosse, juntamente com as professoras. A insegurança e a confusão inerentes ao início das atividades foram dando lugar à iniciativa, ao conhecimento, à autonomia e à autoconfiança. A opção por essa forma de trabalho deu-se em virtude da liberdade, do compromisso e do respeito dos professores, militantes, pesquisadores e da comunidade com o trabalho desenvolvido na escola.

A experiência desenvolvida colocou o desafio de produzir, juntamente com os sujeitos sociais que vivenciam o ambiente escolar nas comunidades rurais, um instrumental capaz de fortalecer o ensino de Geografia e a proposta denominada pedagogia da terra. Esse encaminhamento tem exigido repensar as práticas docentes, ficando como regra o fato de ser fundamental o trabalho coletivo desenvolvido na trajetória planejada. A pesquisa apresentada insere-se nas análises teóricas que discutem a educação do campo como parte constitutiva da luta pela terra presente na história do campesinato brasileiro.

Nota

1 Texto produto de pesquisa financiada pelo CNPq.

\section{Referências}

ARROYO, Miguel. Prefácio. In: CALDART, Roseli. Pedagogia do movimento sem terra. São Paulo: Expressão Popular, 2004. p. 7-16.

ARROYO, Miguel; FERNANDES, Bernardo. A educação básica e o movimento social do campo. Brasília: Articulação Nacional por uma Educação Básica do Campo, 1999.

AZEVEDO, Helena Selma. Identidade resgatada ou nova identidade? 1992. Tese (Doutorado em Sociologia) - Departamento de Sociologia, Universidade Federal do Ceará, Fortaleza, 1992.

CALDART, Roseli. Pedagogia do movimento sem terra. São Paulo: Expressão Popular, 2004.

FERNANDES, Bernardo Mançano. Os campos da pesquisa em educação do campo: espaço e território como categorias essenciais. In: MOLINA, Mônica Castag- 
na. Educação do campo e pesquisa: questões para reflexão. Brasília: MDA, 2006. p. 27-39.

LEITE, Sérgio et al. Impactos dos assentamentos: um estudo sobre o meio rural brasileiro. Brasília: IICA/NEAD; São Paulo: Unesp, 2004.

MAIA, Lucíola Andrade. Mística, educação e resistência no Movimento dos Sem-Terra. Fortaleza: Edições UFC, 2008.

OLIVEIRA, Alexandra Maria de. Trajetórias camponesas: trabalho e educação em assentamentos rurais. In: ENCONTRO NACIONAL DE GEOGRAFIA AGRÁRIA, 19, 2009, São Paulo. Anais. São Paulo: Laboratório de Geografia Agrária/DG/FFLCH/USP, 2009. p. 1-20.

OLIVEIRA, A. M.; SILVA, E. V. Geografia e escola do campo: saberes, práticas e resultados. Mercator (Fortaleza), v. 8, n. 16, p. 177-186, 2009.

OLIVEIRA, Ariovaldo Umbelino de. As transformações territoriais recentes no campo brasileiro. São Paulo: [s.n.], 1998. p. 1-28.

PONTUSCHKA, Nídia Nacib; OLIVEIRA, Ariovaldo Umbelino de (Orgs.). Geografia em perspectiva. São Paulo: Contexto, 2002.

RAFFESTIN, Claude. Por uma geografia do poder. Ática, São Paulo, 1993.

STEDILE, João Pedro; FERNANDES, Bernardo Mançano. Brava gente - a trajetória do MST e a luta pela terra no Brasil. São Paulo: Ed. Fund. Perseu Abramo, 1999.

Alexandra Maria de Oliveira - Doutora em geografia humana pela Universidade de São Paulo e professora adjunto II na Universidade Federal do Ceará. 